\title{
The Public, the Private and the Changing Expectations for Everyday Welfare Services: The Case of Finnish Parents Seeking Private Health Care for their Children
}

\author{
Liina Sointu*, Turo-Kimmo Lehtonen** and Liisa Häikiö*** \\ *Faculty of Social Sciences, Tampere University, Finland \\ E-mail: liina.sointu@tuni.fi \\ ${ }^{* *}$ Faculty of Social Sciences, Tampere University, Finland \\ E-mail: turo-kimmo.lehtonen@tuni.fi \\ ***Faculty of Social Sciences, Tampere University, Finland \\ E-mail: liisa.haikio@tuni.fi
}

This article sheds light on a policy area where the notion of the active citizen has gained prominence as part of the transformation of the welfare state: purchasing private health services and private health insurance for children in Finland. Although the country's universal health care system offers free primary health care for children, 40 per cent of children now have private insurance. Drawing on interviews with parents who seek private solutions, we examine what they perceive to be good health care. Our analysis reveals that parents are looking for certain practices - in Finland available only in the private sector - that they see as signs of good care. The unavailability of these practices in public health care calls into question the access, quality and efficiency of the public system. Based on these findings, we discuss the possible consequences of the disparity between parents' expectations and the universal health care system.

Keywords: Private health insurance, health care, active citizenship, welfare state change, universalism.

\section{Introduction}

Health and social care policy is a core area in which welfare state change has occurred in many European countries. In Finland, these policies now increasingly rely on active citizens who are encouraged to become more self-sufficient in arranging services for themselves (Mattila, 2011; Brennan et al., 2012; Harjula, 2016). While transformations at the policy level have been mapped out in research (e.g. Martinussen and Magnussen, 2009; Ranci and Pavolini, 2013), less is known about their connections to and consequences for the everyday lives of families.

One area of study that has drawn attention to the perspective of everyday life is approaching welfare state changes as emotional reform (Tonkens et al., 2013). By emotional reform, Tonkens et al. (2013: 407) mean that welfare state retrenchment occurs not only in relation to rules, rights and entitlements but also to people's experiences of cutbacks in public services and what they feel they are entitled to. The emotional and practical implications of retrenchment have been explored particularly in the area of long-term social care (Tonkens, 2012; Grootegoed, 2013; Grootegoed et al., 2013). 
In this article, we seek to shed light on another policy area where a change is underway, where the notion of active citizen has gained prominence and where everyday practices are intimately linked with emotional experiences: children's primary health care in Finland. Although Finland's tax-funded universal health care system offers free primary health care for children, many parents seek private solutions alongside or apart from public health care (Valtonen et al., 2014; Järvelin et al., 2015). Around 40 per cent of Finnish children now have private insurance to cover the costs of services at the primary level of health care. In addition, children under three are the largest user group of private health care services in Finland.

Our main questions are the following. Drawing on interviews with parents who seek private solutions in arranging their children's primary health care, we ask what these parents perceive as good and competent health care. Since private health insurance for children plays such a significant role in the primary health care puzzle for families in Finland (Valtonen et al., 2014; Lehtonen, 2017), we also ask how perceptions of health care service are intertwined with private health insurance. We read the parents' perceptions from the premise that their relationship with the issue of their children's health care is affect-laden. By this we mean that this relationship is imbued with a wide range of emotions, ranging from worry to relief through an overarching affection for the child; however, this relationship is shaped not just by first-hand experiences but also by media discussions, insurance companies and conversations with friends, among other factors (cf. Lupton, 2011; Sointu, 2015).

Parents' relationship with the issue is affect-laden also in the sense that the health care choices and encounters are considered to affect children's current and future well-being. This idea seems to be connected to contemporary middle-class parenting culture, which has been described as intensive (e.g. Faircloth, 2014). This refers to the fact that children are perceived to require significant emotional and economical investment from their parents, as well as active measures to ensure their optimal physiological, social and psychological development (Hays, 1996; Lee et al., 2010; Lee, 2014; Faircloth, 2014). Furthermore, there is an underlying 'risk consciousness' through which children, including foetuses, are perceived in middle-class parenting (Lee, 2014: 11). Children are seen to be 'at risk', although the exact nature of the risk is uncertain. Parents' responsibility, then, is to take an active approach to managing risk in co-operation with experts on child development (Lee, 2014: 12).

Against this background, private health insurance can be seen as a risk management tool for parents. While uncertainty about children's wellbeing is something that concerns all parents regardless of their socioeconomic position, families with different educational and economic backgrounds may rely on different and class-specific strategies in pursuing security (see Cooper, 2014). In Finland, the majority of those who purchase private health insurance have higher or mid-level education (Valtonen et al., 2014: 30). They also tend to have higher income (Kajantie, 2019), although in children's case the educational level of parents is more important than income (Valtonen et al., 2014: 21, 30). According to qualitative study by Lehtonen (2017: 693-4), families who do not take out policies cite as their main reason the confidence that they have in the public system, which they find wellfunctioning. Furthermore, they see this system as a valuable part of the welfare state, which they wish to support and in which they wish to take part. Compared to those who have taken out insurance policies, they often mention economic calculations behind their solution, stating that insurance is too expensive for them or unprofitable. The popularity of 
insurance among those with higher or mid-level education may contribute to its status as a 'middle-class thing' (Lehtonen, 2017: 706).

By examining parents' perceptions of good health care in this context, we shed light on the expectations that families have for the health care system and thus add to the understanding of the 'emotional subtext of welfare state change' (Tonkens et al., 2013: 407). Our perspective is novel in two ways. Firstly, previous studies have largely focused on social care for (older) adults when exploring the consequences of welfare state retrenchment and the new care and welfare order (Newman and Tonkens, 2011). Less research exists on welfare services related to children. Yet the case of children's private health care in Finland contains all three elements central to the new care and welfare order: choice, responsibility and participation (Newman and Tonkens, 2011). Secondly, instead of retrenchment and its consequences, we focus on the perspective of those who willingly assume the role of 'active citizen' by seeking more choice, participation and responsibility outside the public system. By carefully examining what these parents perceive as good health care, we learn about middle-class expectations and how they could challenge the universal system if they become widespread.

The article proceeds in the following manner. We begin by examining the context of the study, the main features of Finland's universal health care system in relation to the Finnish welfare state. Then, after describing our data and methods, we present three main sections that analyse what our informants conceive as good and competent health care; elements related to access, quality and efficiency are central. To conclude, we discuss the disparity between these parents' expectations and what the universal health care system in Finland offers.

\section{Choice within the universal health care system in Finland}

As in other Nordic countries, the history of the Finnish health care system is closely connected to the development of the welfare state and the principles of universalism and equality (Häkkinen and Lehto, 2005; Kvist and Greve, 2011; Anttonen et al., 2012: 5). In the Finnish state-based and mainly tax-funded health care system, municipalities have the legal responsibility for providing the relevant services to their populations (for an overview of the Finnish system, see Tynkkynen et al., 2016).

Children's primary health care is provided in four locations: municipal health centres, public child health clinics, private clinics and casualty departments. Within the public system, health care centres, run by either a municipality or a private company if outsourced, are where children's illnesses are treated. Health care centres are open during office hours; at other times, acute cases are treated in casualty departments. Public children's health clinics do not offer outpatient services; instead, they monitor the overall physical, social and psychological well-being of the child and family and carry out vaccination programmes. Health care for children in municipal health care centres is free of charge, and the costs of specialised health care are heavily subsidised. Additionally, all children are covered by National Health Insurance, which partially reimburses the costs of private health care and prescription drugs. However, the average reimbursement rate is low at approximately 25 per cent of the expenses (Tynkkynen et al., 2016: 229).

In systems like Finland's, the rationing of access to services through waiting times is a form of cost control (Moran, 2000: 150; Tynkkynen et al., 2018: 487). Long waiting times are in fact seen as a persistent problem in the Finnish municipal health care system 
(European Commission, 2017: 8; Tynkkynen et al., 2018: 489). Another typical feature is that access to a doctor is relatively tightly regulated (Reibling and Wendt, 2012); one cannot simply choose a doctor with whom to get an appointment, and access to a specialist requires a referral. In primary health care, children are treated by public health nurses and general practitioners; unlike in some other European countries, there are no specialists, such as paediatricians, working in public primary health care in Finland (Thompson et al., 2013: 30-32).

The Finnish health care system in its current form was created in the 1960s and 1970s, and several attempts have been made to renew the system in the 2010s. Extending choice in the health care system has been on the political agenda, but choice remains rather limited in practice. Currently, patients in public primary health care are allowed to change their health care centre every twelve months (Tynkkynen et al., 2016: 227), and they cannot choose the doctor from whom to seek a consultation. Along with the demand for more choice, an atmosphere of 'permanent austerity' (Pierson, 2001) marks the discussions of Finland's health care system and its future.

In practice, families with children have sought choice outside the public system using private health care services purchased out of pocket and/or with private health insurance. Such private health insurance products came into the market in the mid-1980s. Presently approximately 1.2 million Finns have private health insurance, of whom 497000 are children (individually purchased), 455000 are adults who have purchased their policy individually and 245000 are adults whose employers have purchased their policy (Federation of Finnish Financial Services, 2019). Policies are mostly used to cover private doctor's fees, medicines and the costs of medical tests prescribed by a doctor (Valtonen et al., 2014: 20). The up-take of insurance for children has increased from 398000 children in 2009 to 438000 in 2013 and 497000 in 2018 (Federation of Finnish Financial Services, 2019). The current number corresponds to approximately 40 per cent of children in the country.

Parents who purchase private insurance for their children mostly have a mid-level or higher education and higher income (Valtonen et al., 2014: 30; Kajantie, 2019). The cost of insurance is approximately 350-400 euros per year with deductibles around 100-150 euros per year. Almost all children's appointments in private clinics are specialist appointments (Järvelin et al., 2015: 3203), and the specialist fees vary between approximately 90-140 euros per visit. According to recent estimations, private health insurance is unprofitable for families with children in purely financial terms (see Kajantie, 2019). Families can make several private doctor visits without exceeding the price of insurance. However, as we suggested in the introduction, insurance may 'pay off' in other ways: such as serving as a risk management tool for parents who want to take and show responsibility in ensuring that their children receive the best possible care. It may also provide convenience, comfort and security for families as they piece together the puzzle of their hectic everyday schedules at work and home (see Lehtonen, 2017).

In parallel with the popularity of private health insurance, private providers have established their position in primary health care for children especially in the urban areas of southern Finland where around 20-30 per cent of children only use private health care (Järvelin et al., 2015). As a whole, children under three years of age are the largest user group of private health care in Finland (Miettinen et al., 2013: 5; Kajantie, 2014). Against this background, it is important to take a closer look at the expectations of this group who 
actively seek private solutions, as this can inform us about the possible future challenges for the public welfare services.

\section{Data and methods}

Our study is based on two projects (see Acknowledgment for details) in which we interviewed a total of seventy parents about their children's health care in 2013 and 2014. The purpose of this article is to shed light on the expectations of families who seek private solutions for their children's health care, so we have chosen to limit our analysis to interviews with the forty-five parents who had private health insurance policies for their children and who use private services. They all live in Greater Helsinki and the Tampere region, which are among the areas in Finland where it is common to have private health insurance for children. Of these parents, seventeen were individually interviewed, and twenty-eight participated in focus group interviews. All parents who were individually interviewed were women. Of the interviewees in the focus groups, seventeen were women and eleven were men. Interviewees were between twenty and forty years old.

The interviewees in the focus groups were recruited by Taloustutkimus Ltd (see Lehtonen, 2017: 708). The individual interviewees were found by university students among their social circles. Based on the information provided by the interviewees about their educational and vocational background, the interviewees can be described as middle-class. They were mostly well-educated with average to high income. Those with lower income were mostly students who were studying for university degree. For some of them the insurance policy was purchased by their own parents as a gift for the grandchildren.

The focus group and individual interviews were semi-structured, although individual interviews were more strictly structured. Interviews were recorded and transcribed verbatim. The themes discussed in the focus group and individual interviews included parents' thoughts about and experiences of private health insurance and their children's health care. Focus group interviews lasted from one and a half to two hours, while individual interviews were significantly shorter, lasting from ten to twenty minutes. The reason for such a short duration is that individual interviews were carried out by social policy students as part of a seminar. Interview questions were designed by students and teachers (authors one and three) in class, and the data collection process was closely supervised by the teachers. Despite the brevity, interviews were thematically rich, reflecting the same themes and concerns as focus group interviews (see also Lehtonen, 2017).

Focus group interviews provide insights into experiences, perceptions and beliefs connected to certain actions (Carey and Asbury, 2016: 17). When analysing focus group data, one has to pay attention to group dynamics. However, according to Carey and Asbury (2016: 82), data is only significantly affected by dynamics in certain cases, such as when participants are in vulnerable positions or when there are differences in the status of participants. In our case, the focus group interviews were put together so that those who had taken out insurance had separate sessions from those who had not. In this way, the groups consisted of people with like-minded ideas about children's health care. The discussions did not involve much controversy but were geared more towards a consensus, although the participants did sometimes express differences in opinion. 
For the purposes of this study, we focused on the parents' perceptions of their children's health care services and how they are connected to private insurance. An important premise for our analysis is that the parents' relationships with their children's health care are affect-laden (Sointu, 2015), implying that the health care of one's child is a personal matter to a parent, who feels responsible for the child. It is thus different from organising generic health care for all potential patients. For families, actual encounters with health care organisations are important, but so are their conceptions of these encounters. These conceptions are imbued with a wide range of emotions like worry, relief and profound affection for the child. Ideas and sentiments about what is deemed good health care are shaped not only by first-hand experience but also by media discussions, conversations with friends, insurance companies, social media and advertising (Lupton, 2011; Lehtonen, 2017).

In the analysis, we seek answers to the following questions: What are the features of a good and competent health care service for children, according to the interviewed parents? How are perceptions of the competent health care service intertwined with private health insurance? After familiarising ourselves with the data, we carried out a thematic framework analysis (Spencer et al., 2013). We began by using mind maps to identify aspects related to the health care encounter that appeared important to the interviewees. At this point, we noticed that the parents frequently commented on concrete practices like those related to booking appointments or obtaining referrals. Therefore, we decided to pay attention to them as we systematically classified these aspects using the qualitative data analysis software program Atlas.ti. Finally, we formed three main categories, each of which represents one key feature of what parents conceived as good and competent health care: access, quality and efficiency. Access was the most prominent in parents' reasoning. Each feature connects to specific practices contributing to the competence of the health care service and connecting to private health insurance. These features are illustrated in the sections that follow.

In conducting our research, we followed the ethical guidelines of the Finnish National Board on Research Integrity (2009), including respecting the autonomy of the research subjects, avoiding harm and protecting privacy of the participants. Interviewees were informed about voluntariness of participation, and all signed an informed consent. All names have been changed to protect the interviewees' anonymity.

\section{Security and comfort through quick access}

Access was a key element of good health care for the interviewed parents. They reported that they felt that there was uncertainty around secure access to public health care. This uncertainty concerned both the initial assessment in the health care centre and the referrals to special care. Other issues were at play, as well, including access to doctors, the level of care available in the public sector and the way in which parents can take and demonstrate responsibility for providing the best possible care for their children. A reference to 'not getting an appointment' was often made by the interviewees, especially in situations of non-urgent care:

For example, last time we went to the doctor when there was some blood in my one-year-old son's diaper, I tried to go to the public side first, but we didn't get an appointment so that's why we went to the private side. (Marja, individual interviews) 
To a concerned parent, not obtaining an appointment promptly equals not getting an appointment at all, especially given the option of going to a private clinic, where access is known to be certain and rapid. An important context for this experience of uncertainty is how the public system is organised and how access entails several phases: first, nurses who act as gatekeepers initially assess the need for a doctor's appointment, either by phone or in person; then, the patient is given an appointment with either a nurse or a general practitioner.

What the parents found especially unpleasant was having to justify their child's need for health care. Some mentioned that they felt that they had to beg or fight for an appointment or referral. Paula, a mother of two, explains:

When you go the public health care centre and you ask for a referral to special health care, you have to pray for it. But when you go to the private clinic and the doctor finds that there's wheeze in the lungs, she writes the referral and you can go to the specialized health care just to check it, just in case. (Individual interviews)

The idea of begging or exaggerating the symptoms made the parents feel uneasy, especially when they thought that 'it should be self-evident that you get the referral' (Hanna). However, the idea that obtaining a referral to a specialist should be obvious is relatively novel in Finland. Its emergence has to do with the way in which expectations regarding the quality of health care have changed through the services that private sector has been able to offer. It is easier to obtain a referral from private clinics than from public health care centres, and - with an insurance policy - the additional private consultation does not come with any additional cost. With the availability of these services, the perception of standards and expectations regarding good care have been upgraded. Moreover, it can be speculated that, for the parents, the mere availability of private insurance suggests that what they receive from the public sector may not be up to par:

I thought private insurance is important because even when we were expecting the baby, it already seemed that the public health care centres could not necessarily respond to all of the care needs, at least not with the intensity or schedule that I as a parent of a little child would want. (Anne, individual interviews)

While waiting was considered unpleasant by the parents, it was a special source of anxiety when associated with uncertainty about what was wrong with a child and whether the condition could get worse with time. Leena elaborated on this point as follows:

Problems can unexpectedly grow to be quite big. I've heard that in the public side you don't necessarily get examined that quickly. I thought that the insurance policy is there just to be on the safe side, even if we wouldn't use it. I feel that it brings security, to know that if I start to worry about something, then I can get the problem examined almost right away. (Individual interviews)

The interviews revealed how the option of private health care, made easily available by private insurance, not only reduces the experience of uncertainty but also promises security and comfort. Natalier and Willis (2008: 407) claim that purchasing a private policy implies engaging in a 'symbolic act' that creates a relationship or bond between individuals and the private health care company; this relationship is filled with positive 
expectations and trust in private health care. Marketing for private health insurance tends to emphasise that the insurance policy enables quick access to health care and thus minimises the need to worry about access in the first place (see Harley et al., 2011: 315).

Such a symbolic bond was clearly present in our interviews. In the specific case of children's health care in Finland, insurance promises more rapid and secure access to treatment than what the public side can offer. Parents who have purchased the insurance conceive that it is precisely the insurance policy that gives them access to private clinics. Of course, they would have access to private clinics without it as well, simply paying the fees out of pocket. In financial terms, taking into account the cost of insurance and deductibles, they might be better off without the insurance product (see Kajantie, 2019). Still, insurance delivers on its promise in terms of bringing comfort to parents who feel responsible for guaranteeing the best possible care for their children. With insurance as a backup, one can simply take children to the private clinic for a check-up without having to think about the expense - at least, not on the spot - or the possibility of 'annoying the

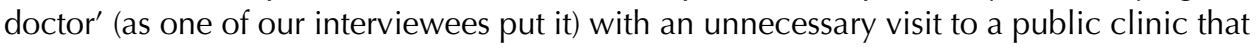
might be overloaded with patients.

To sum up this section, insurance lets parents feel that they have guaranteed entry to private health care services that offer comfort and convenience through the possibility of choosing one's doctor and time of the appointment. However, positive expectations about private health care also involve another key feature of good health care: quality, the focus of the next section.

\section{Quality through specialised, child-centred services}

For many of the interviewed parents, sufficiently high quality of health care implies the highest possible quality; even for relatively simple health issues, it seems best to receive attention for the child from a specialist like a paediatrician. This is possible in the private clinics. Currently, 90 per cent of children's appointments in Finland's private clinics are specialist appointments (Järvelin et al., 2015: 3202). This is in striking contrast with public primary health care, where the first professionals one meets are nurses or general practitioners instead of specialists; moreover, nurses are playing an increasingly important role in place of general practitioners (Sinervo et al., 2016: 120).

The nurses' and general practitioners' expertise were a cause of concern for some of the interviewed parents. Even those who did not explicitly express unease mentioned that, on certain occasions, it was more convenient to book an appointment directly with a specialist:

We have gone straight to the private side to see a specialist, to get an answer. It has been easier that way, when you have a problem with ears, for example, that you make an appointment with an otologist and you don't get bounced around. (Päivi, individual interviews)

Based on their knowledge of their children's previous illnesses, the interviewees often considered themselves capable of judging the level of medical expertise required. Therefore, nurses and general practitioners may not be deemed competent enough for a parent who expects a specialist to examine a child. This is how Riina put it: 
In the private clinic you can choose if you suspect that the child has an ear infection, you can access the one doctor who specializes in children. In the public sector, it could be whoever. You wait in line, and then the doctor can be anyone. (Individual interviews)

For our informants, expertise is a matter of individual doctors' education and experience in the specialty area or with children as patients. Parents wish to choose a doctor or clinic based on information they have gathered from their social network and their own experiences.

Riina's remark reflects another important aspect of quality that came up in the interviews: parents look for health care encounters that respond to the child as a special kind of patient, distinct from adults. Marja, for example, notes that 'if you're not used to working with kids, then you don't necessarily know how to act with them'. This comment conveys the idea that encountering, examining and treating children is different in important ways from treating adults - and that this difference should be reflected in health care service.

The interviewees also evaluated the preparedness of health care delivery to respond to children's needs from the perspective of spatial organisation. In municipal health care centres, queuing takes place in waiting rooms. Acute cases like inflammations are treated in casualty departments if they occur outside office hours. In public waiting rooms, children are exposed to the more marginal elements of Finnish society, and parents want to protect their children from seeing 'too much'. Heidi and her children had once witnessed a disoriented and aggressive patient being brought in while in restraints. When reflecting on why she uses private services, she recalled the incident:

We go to the private clinic $X$ because it's so close, so it's nice to go with the kids. And there are other child patients there, and no one in handcuffs there. And there are play areas for children and doctors in their own clothes, so they are not maybe so scary. (Individual interviews)

Unlike public waiting rooms, private clinics provide environments specifically designed for children, which the parents appreciate. Hanna, for example, said that 'it's wrong for the children to have to wait for hours to get to the appointment without any stimuli'.

Overall, private clinics offer care for individual families that they perceive to be of a better quality than what they receive on the public side; specialist-level care and childcenteredness are especially crucial to what the interviewed parents perceived as good quality. Concerns about quality overlapped with concerns of access due to the organisation of public healthcare in Finland, where specialist-level care and seeing a specific doctor by choice are impossible at the primary level.

\section{Efficiency through swift procedures}

In addition to access and quality, the parents identified efficiency as an important feature of good health care service. They want a swift process without unnecessary steps along the way. Appointments with nurses and general practitioners seemed to hinder efficiency, forcing families to go to many appointments instead of just one.

This became particularly clear when the parents talked about recurring ear infection, a common childhood affliction in Finland (see Miettinen et al., 2013: 15). The 
interviewees often cited the risk of ear infections as one reason for obtaining a private health insurance policy when expecting a child. Usually, these infections are treated with antibiotics and/or analgesics. If the infection is chronic, the normal procedure is a tympanostomy, in which a small tube is inserted into the eardrum. This procedure, however, is not performed by the public system unless the infection recurs three times within six months (The Current Care Guidelines, 2019). Some parents we interviewed considered having to wait for the procedure to be both inefficient and unacceptable for children's well-being:

If you want to put the tubes into the ear without insurance there has to be a dreadful amount of infections first. You have to get many courses of antibiotics before they agree to do it. That's where the insurance is useful. (Marko, focus groups)

Without insurance, the cost of a tympanostomy in a private clinic would be around 1000 euros for a family, and many would rule that option out as simply too expensive. However, the procedure is widely available for those who have private insurance. In contrast, in the public sector, access to tympanostomy is more strictly regulated. In addition to medical effectiveness, regulation is related to the logic and purpose of public health care, which differs from private health care. Given limited funding, the public system aims to provide care to meet the needs of the entire population. In contrast, private health care can expand to accommodate all kinds of needs if and when they are financially covered for all those who can afford them:

I think we had to pay around eighty euros for the procedure, the rest was covered by the insurance. But on the public side, we would have been on the waiting list, and anyway this principle that you have to have three ear infections, even when it is evident that there is a structural problem in the ear. It was a big deal to me that we were able to go to the private side and have a doctor who is specialized in kids. She said: there's no point in waiting for more infections. (Lilja, focus groups)

For the interviewees, efficient care meant a thorough examination as early as possible to avoid unnecessary suffering. For an individual parent, it makes sense to perform the most extensive treatment as quickly as possible. However, what is a desirable good for individual families and private clinics might not be beneficial for the collective, because the good in question can imply inefficient and unequal use of public resources.

Thus, there is a contradiction between efficiency at the level of the everyday life of a family and at the level of the population as a whole. This contradiction was also acknowledged by the interviewed parents who conveyed that, on one hand, they felt responsible for securing efficient treatment for their own families, even as, on the other, they felt responsible as citizens to ensure an efficient system and equal care for all children, not just their own.

\section{Conclusion}

In sum, our analysis demonstrated that parents are looking for certain practices that indicate good care, including quick access to a doctor based on parents' own assessments 
of their children's needs, direct access to specialist-level and child-centred care and easy availability of referrals and certain medical procedures. What is common to these practices is that in Finland they are offered only in private health care, where they are made readily available by private insurance. For the interviewed parents, the lack of availability of these practices in public health care centres raises issues of not only access and quality but also efficiency in the public system.

Based on our qualitative study, it is impossible to make statistical generalisations about how widely shared these expectations are; for that, a nationally representative survey would be required. Nevertheless, our study shows that these expectations clearly exist among Finnish families who use private health care. It also shows how the ordinary pursuit of security, comfort and convenience in the daily lives of families is connected to private health care, private insurance and expectations for health care.

To conclude the article, we elaborate on some of the possible unintended consequences of the disparity between parents' expectations and what the universal health care system has to offer. One of the founding ideas of universal health care is that, in principle, the same system is intended to be used by all social groups regardless of social class and on the basis of care needs (Anttonen et al., 2012). Needs, however, are 'ambiguous and elastic' and 'rest upon established social consciousness and shared meanings; as such they are contingent on social changes' (Vabø and Szebehely, 2012: 122; see also Fraser, 1989). Based on our findings, we raise the question of a possible dynamic in which increasing reliance on private solutions in children's health care ends up affecting the norms and standards for care by making available and normalising certain practices that are not part of the public system. These new practices, such as direct access to specialists, may then become a new standard, the level of quality that now should be expected. Ultimately, the level of expectations may become raised for all parents. This may create pressure on families to seek private care.

However, private health services and private insurance are simply not attainable for everyone. First, not all families can afford them; second, not all families are considered healthy enough to be granted insurance by an insurance company. Those with private health insurance tend to be healthier and wealthier (Kiil, 2012; Valtonen et al., 2014). Thus, families are in unequal positions with regard to the pursuit of their health security. The universal health care system found in Nordic countries has managed the health risks of the population in a particular way: relying on a tax-financed organisation of collective health security in which entitlement to health care is based on citizenship instead of social status. The dynamics of access to health care services are altered if - instead of the public health care staff - it is private insurance that operates as the gatekeeper (cf. Heimer, 2002: $117,139)$.

There might also be a risk of erosion of the legitimacy of and trust in public primary health care. Policy feedback research has shown that inclusive welfare policies are connected to a high level of support for the welfare state (Jordan, 2013: 146). In other words, to feel solidarity with the aim of keeping the public system robust, people need to have positive contacts with that system. As Newman and Clarke (2009: 4, 184) suggest, public services can act as important mediums of 'publicness', shaping and sustaining solidaristic attachments and collective identities. If large numbers of people gradually become detached from the universal system in their everyday practices, this may end up affecting how people feel about the system in general and whether they can rely on it (cf. Taylor-Gooby, 2006: 101; Ward, 2019). 
By shedding light on the expectations that middle-class families have for their children's health care services, we have added to the understanding of welfare state change as it connects to everyday experiences, practices and concerns that people have. Throughout the interviews, parents conveyed their sense of responsibility as parents to ensure the best possible care for their children. With the backup of private health insurance and private services, they can not only take but also demonstrate this responsibility. For middle-class families, private insurance and services offer a medium for 'doing security' that involves a rationality of both emotion and reason (cf. Cooper, 2014).

However, these same parents also acknowledged that all children should be entitled to these services, not just their own. This finding points to a distinction between active and activist citizens (Newman, 2011). Whereas active citizens are mostly responsible for their private matters acting through private encounters, activist citizens act together to pose a collective challenge to change the service system. Private insurance supports a limited role for active citizens as it opens a way for private arrangements instead of making collective demands for public health care to respond to families' needs. This internal tension within the notion of being an active citizen is reflected in parents' everyday experiences: as people are increasingly encouraged to act as consumers in relation to welfare services and assume more responsibility for their families, they may begin to feel entitled to demand services that are as extensive as possible, even as they recognise as welfare state citizens that to provide the same possibilities to everyone would be an inefficient use of public resources.

The present study poses an interesting question for research into welfare state change as emotional reform (Tonkens, 2012; Grootegoed, 2013; Tonkens et al., 2013). Although emotions and emotional labour were not the explicit focus of our analysis, we noted disappointment, frustration and anger when parents were denied care that they felt it was reasonable to expect. It would be worthwhile to explore further these emotions among the middle class and their relationship to welfare state institutions to learn more about the disparity between citizenship regimes (cf. Tonkens, 2012) in the level of ideas and practices and what the public system has to offer in concrete terms.

In addition, more research is needed into how private health insurance instruments mediate expectations for health care and citizens' relationship to both public and private health care institutions. Until now, the idea of Nordic service universalism has been to provide health and social care that is not only available and affordable but also attractive to all social groups (Vabø and Szebehely, 2012: 121). The aim has been to 'promote an equality of the highest standards, not an equality of minimal needs' (Esping-Andersen, 1990: 50), to provide services and benefits to meet the needs of the demanding middle class within the public system to discourage private solutions (Vabø and Szebehely, 2012). By encouraging practices that are not feasible within the public system, private health insurance may make it more difficult for the universal health care system to keep up with the expectations of the middle class.

\section{Acknowledgments}

This work was supported by Academy of Finland ('Insurance and the Problem of Insecurity' project, grant number 283447) and by The Social Insurance Institution of Finland ('Between universalism and choice: Why do families use private health care 
services' project, Kela KKRL $12 \S$ research funds). The authors would like to thank the students for conducting the individual interviews, and the three anonymous reviewers for their insightful comments.

\section{References}

Anttonen, A., Häikiö, L., Stefánsson, K. and Sipilä J. (2012) 'Universalism and the challenge of diversity', in A. Anttonen, L. Häikiö and K. Stefánsson (eds.), Welfare State, Universalism and Diversity, Cheltenham: Edward Elgar, 1-15.

Brennan, D., Cass, B., Himmelweit, S. and Szebehely, M. (2012) 'The marketisation of care: rationales and consequences in Nordic and liberal care regimes', Journal of European Social Policy, 22, 4, 377-91.

Carey, M. A. and Asbury, J. E. (2016) Focus Group Research, London: Routledge.

Cooper, M. (2014) Cut Adrift: Families in Insecure Times, Berkeley: University of California Press.

The Current Care Guidelines (2019) https:/www.kaypahoito.fi/en/ [accessed 21.05.2019].

Esping-Andersen, G. (1990) The Three Worlds of Welfare Capitalism, Cambridge: Polity Press.

European Commission (2017) State of Health in the EU: Finland Country Profile 2017, https://ec.europa.eu/ health/state/country_profiles_en [accessed 21.05.2019].

Faircloth, C. (2014) 'Intensive parenting and the expansion of parenting', in E. Lee, J. Bristow, C. Faircloth and J. Macvarish (eds.), Parenting Culture Studies, London: Palgrave Macmillan, 25-50.

Federation of Finnish Financial Services (2019) Sairauskuluvakuutustilasto, http://www.finanssiala.fi/ tilastot/FA-tilasto-sairauskuluvakuutus-2009-2018.pdf [accessed 21.05.2019].

Finnish National Board on Research Integrity (2009) Ethical Principles of Research in the Humanities and Social and Behavioural Sciences and Proposals for Ethical Review, https://www.tenk.fi/en/ethicalreview-in-finland [accessed 11.02.2020].

Fraser, N. (1989) 'Talking about needs: interpretive contests as political conflicts in welfare-state societies', Ethics, 99, 2, 291-313.

Grootegoed, E. (2013) Dignity of Dependence. Welfare State Reform and the Struggle for Respect, Doctoral dissertation, University of Amsterdam.

Grootegoed, E., Bröer, C. and Duyvendak, J.W. (2013) 'Too ashamed to complain: cuts to publicly financed care and clients' waiving of their right to appeal', Social Policy and Society, 12, 3, 475-86.

Häkkinen, U. and Lehto, J. (2005) 'Reform, change, and continuity in Finnish health care', Journal of Health Politics, Policy and Law, 30, 1-2, 79-96.

Harjula, M. (2016) 'Health citizenship and access to health services: Finland 1900-2000', Social History of Medicine, 29, 3, 573-89.

Harley, K., Willis, K., Gabe, J., Short, S. D., Collyer, F., Natalier, K. and Calnan, M. (2011) 'Constructing health consumers: private health insurance discourses in Australia and the United Kingdom', Health Sociology Review, 20, 3, 306-20.

Hays, S. (1996) The Cultural Contradictions of Motherhood, New Haven, CT: Yale University Press.

Heimer, C. (2002) 'Insuring more, ensuring less: the costs and benefits of private regulation through insurance', in T. Baker and J. Simon (eds.), Embracing Risk: The Changing Culture of Insurance and Responsibility, Chicago: University of Chicago Press, 116-45.

Jordan, J. (2013) 'Policy feedback and support for the welfare state', Journal of European Social Policy, 23, 2, 134-48.

Järvelin, J., Virta, L. and Mikkola, H. (2015) 'Hoitoon yksityiselle vai julkiselle sektorille? Alle 7-vuotiaiden lääkärissäkäynnit pääkaupunkiseudulla', Finnish Medical Journal, 70, 47, 3199-206.

Kajantie, M. (2014) 'Lääkäripalveluiden käyttö jakaa väestöä', Hyvinvointikatsaus 4/2014, Helsinki: Statistics Finland, https://www.stat.fi/artikkelit/2014/art_2014-12-08_002.html [accessed 20.1.2020].

Kajantie, M. (2019) 'Yksityisiä sairauskuluvakuutuksia hankitaan yhä enemmän - selvä enemmistö jää tappiolle', Tieto \& Trendit, 23 January, http://www.stat.fi/tietotrendit/artikkelit/2019/yksityisiasairauskuluvakuutuksia-hankitaan-yha-enemman-selva-enemmisto-jaa-tappiolle/?listing=simple [accessed 16.12.2019]. 
Kiil, A. (2012) 'What characterises the privately insured in universal health care systems? A review of the empirical evidence', Health Policy, 106, 1, 60-75.

Kvist, J. and Greve, B. (2011) 'Has the Nordic welfare model been transformed?', Social Policy and Administration, 45, 2, 146-60.

Lee, E. (2014) 'Introduction', in E. Lee, J. Bristow, C. Faircloth and J. Macvarish (eds.), Parenting Culture Studies, London: Palgrave Macmillan, 1-22.

Lee, E., Macvarish, J. and Bristow, J. (2010) 'Risk, health and parenting culture', Health, Risk and Society, $12,4,293-300$.

Lehtonen, T-K (2017) 'Domesticating insurance, financializing family lives: the case of private health insurance for children in Finland', Cultural Studies, 31, 5, 685-711.

Lupton, D. (2011) 'The best thing for the baby: mothers' concepts and experiences related to promoting their infants' health and development', Health, Risk and Society, 13, 7-8, 637-51.

Martinussen, P. and Magnussen, J. (2009) 'Health care reform: the Nordic experience', in J. Magnussen, K. Vrangbaek and R. Saltman (eds.), Nordic Health Care Systems: Recent Reforms and Current Policy Challenges, Maidenhead: Open University Press and McGrawHill, 21-52.

Mattila, Y. (2011) Suuria käännekohtia vai tasaista kehitystä? Tutkimus Suomen terveydenhuollon suuntaviivoista, Helsinki: The Social Insurance Institution of Finland.

Miettinen, J., Tervola, J., Virta, L., Koskinen, H., Tuominen, U., Maljanen, T. and Mikkola, H. (2013) Sairaanhoitovakuutuksen korvaamien yksityisten terveyspalvelujen käytön kehitys ja hintavertailu, Helsinki: The Social Insurance Institution of Finland.

Moran, M. (2000) 'Understanding the welfare state: the case of health care', The British Journal of Politics and International Relations, 2, 2, 135-60.

Natalier, K. and Willis, K. (2008) 'Taking responsibility or averting risk? A socio-cultural approach to risk and trust in private health insurance decisions', Health, Risk and Society, 10, 4, 399-411.

Newman, J. (2011) 'Mobilising the active citizen in the UK. Tensions, silences and erasures', in J. Newman and E. Tonkens (eds.), Participation, Responsibility and Choice. Summoning the Active Citizen in Western European Welfare States, Amsterdam: Amsterdam University Press, 107-25.

Newman, J. and Clarke, J. (2009) Publics, Politics and Power. Remaking the Public in Public Services, London: Sage.

Newman, J. and Tonkens, E. (2011) 'Active citizenship. Responsibility, choice and participation', in J. Newman and E. Tonkens (eds.), Participation, Responsibility and Choice. Summoning the Active Citizen in Western European Welfare States, Amsterdam: Amsterdam University Press, 179-200.

Pierson, P. (2001) The New Politics of the Welfare State, Oxford: Oxford University Press.

Ranci, C. and Pavolini, E. (eds.) (2013) Reforms in Long-Term Care Policies in Europe Investigating Institutional Change and Social Impacts, New York: Springer.

Reibling, N. and Wendt, C. (2012) 'Gatekeeping and provider choice in OECD healthcare systems', Current Sociology, 60, 4, 489-505.

Sinervo, T., Tynkkynen, L-K and Vehko, T. (eds.) (2016) Mitä kuuluu peursterveydenhuolto? Valinnanvapaus ja integraatio palvelujen kehittämisen polttopisteessä, Helsinki: National Institute for Health and Welfare, Report 16/2016.

Sointu, E. (2015) 'Discourse, affect and affliction', The Sociological Review, 64, 2, 312-28.

Spencer, L., Ritchie, J., O'Connor, W., Morrel, G. and Ormston, R. (2013) 'Analysis in practice', in J. Ritchie, J. Lewis, C. McNaughton-Nichols and R. Ormston (eds.), Qualitative Research Practice, London: Sage, 295-346.

Taylor-Gooby, P. (2006) 'Trust, risk and health care reform', Health, Risk and Society, 8, 2, 97-103.

Thompson, M., Gill, P., Bruel, van den A. and Wolfe, I. (2013) 'Primary care for the children', in I. Wolfe and M. McKee (eds.), European Child Health Services and Systems: Lessons without Borders, Maidenhead: Open University Press and McGraw-Hill Education, 27-62.

Tonkens, E. (2012) 'Working with Arlie Hochschild: connecting feelings to social change', Social Politics, $19,2,194-218$. 
Tonkens, E., Grootegoed, E. and Duyvendak, J.W. (2013) 'Introduction: welfare state reform, recognition and emotional labour', Social Policy and Society, 12, 3, 407-13.

Tynkkynen, L-K., Alexandersen N., Kaarboe O., Anell, A., Lehto, J. and Vrangbæk, K. (2018) 'Development of voluntary private health insurance in Nordic countries - an exploratory study on country-specific contextual factors', Health Policy, 122, 5, 485-92.

Tynkkynen, L-K., Chydenius, M., Saloranta, A. and Keskimäki, I. (2016) 'Expanding choice of primary care in Finland: much debate but little change so far', Health Policy, 120, 3, 227-34.

Vabø, M. and Szebehely, M. (2012) 'A caring state for all older people', in A. Anttonen, L. Häikiö and K. Stefánsson (eds.), Welfare State, Universalism and Diversity, Cheltenham: Edward Elgar, 121-43.

Valtonen, H., Kempers, J. and Karttunen, A. (2014) Supplementary Health Insurance in Finland. Consumer Preferences and Behavior, Helsinki: The Social Insurance Institution of Finland, Working papers 65, http://hdl.handle.net/10138/135958 [accessed 21.05.2019].

Ward, P. (2019) 'Trust: what is it and why do we need it?', in M. H. Jacobsen (ed.), Emotions, Everyday Life and Sociology, London: Routledge, 13-26. 